\title{
Canadian laboratory standards for sexually transmitted infections: Best practice guidelines
}

\author{
Max Chernesky $\mathrm{PhD}^{1}$, David Patrick MD², Rosanna Peeling $\mathrm{PhD}^{3}$
}

$S_{\text {aid }}^{\text {ear }}$ exually transmitted infections (STI) continue to spread, and show no international boundaries. Diseases such as gonorrhea and syphilis, which we thought were under control in Canadian populations, have increased in incidence. Sexually transmitted or associated syndromes such as cervicitis, enteric infections, epididymitis, genital ulcers, sexually related hepatitis, ophthalmia neonatorum, pelvic inflammatory disease, prostatitis and vulvovaginitis present a challenge for the physician to identify the microbial cause, treat the patient and manage contacts. During the past 10 years, new technologies developed for the diagnosis of STIs have provided a clearer understanding of the real accuracy of traditional tests for the diagnosis of infections caused by Chlamydia trachomatis, Neisseria gonorrhoeae, Treponema pallidum, herpes simplex viruses, hepatitis B virus, human papillomaviruses, HIV, Haemophilus ducreyi, Trichomonas vaginalis and mycoplasmas. This has presented a major challenge to the diagnostic laboratory, namely, selecting the most sensitive and specific test matched with the most appropriate specimens to provide meaningful and timely results to facilitate optimal patient care.

The project of creating the articles collated in this issue of The Canadian Journal of Infectious Diseases \&8 Medical Microbiology was considered within the STI/HIV committee of the Canadian Infectious Diseases Society (now evolved into the Association of Medical Microbiology and Infectious Disease Canada). Canadian experts were asked to submit articles focusing on standards of laboratory practices that could be used as guidelines for best practices in diagnostic laboratories in Canada. Each article has been peer-reviewed and appears as the most up-to-date, evidence-based collation of recommendations from the diagnostic literature for STIs. Some readers may have a difference of opinion on some of the conclusions drawn. We see this as a healthy situation which could lead to communication, ongoing debate and dialogue, with more input into future updates.

The current issue contains a paper on STI syndromes with potential etiologies, as well as individual manuscripts dealing with laboratory diagnoses and practices for the modern laboratory. A second issue will continue with papers on laboratory diagnoses and practice, and will also contain papers that discuss special requests related to laboratory diagnosis such as the testing of semen, diagnosis of bacterial vaginosis, investigation of sexual abuse and diagnostic test evaluations.

We would like to thank all of the authors and reviewers for their time on this project, the Canadian Microbiology Laboratory for their support, the Journal for publication, and Colin Hewitt, who acted as the coordinating editor.

${ }^{1}$ Pathology and Molecular Medicine, McMaster University; Medical Microbiology, St Joseph's Healthcare, Hamilton, Ontario; ${ }^{2}$ British Columbia Centre for Disease Control, Vancouver, British Columbia; ${ }^{3}$ World Health Organization, STD Diagnostic Initiative, Geneva, Switzerland

Correspondence: Dr Max A Chernesky, St Joseph's Healthcare, 50 Charlton Avenue East, Hamilton, Ontario L8N 4A6.

Telephone 905-521-6021, fax 905-521-6083, e-mail chernesk@mcmaster.ca 


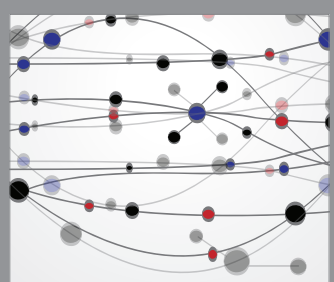

The Scientific World Journal
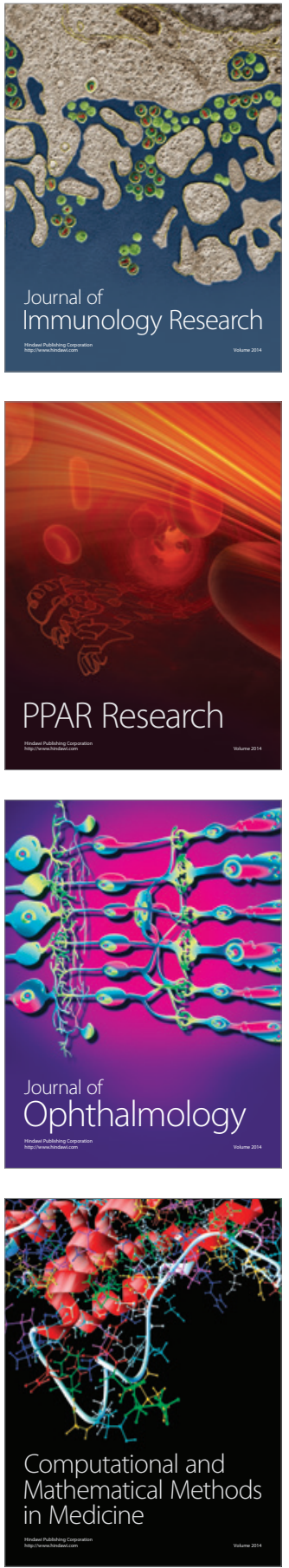

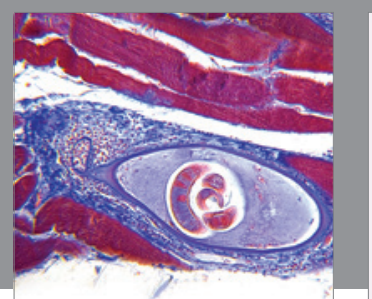

Gastroenterology Research and Practice

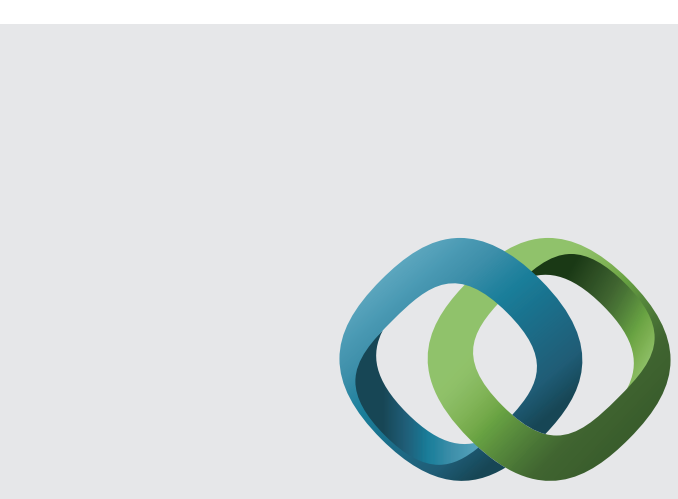

\section{Hindawi}

Submit your manuscripts at

http://www.hindawi.com
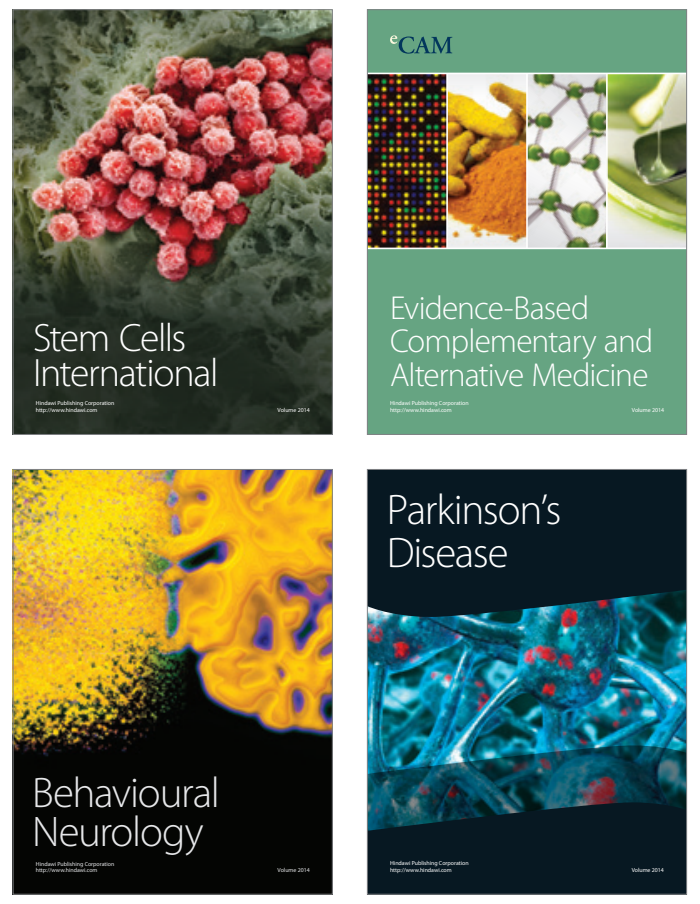
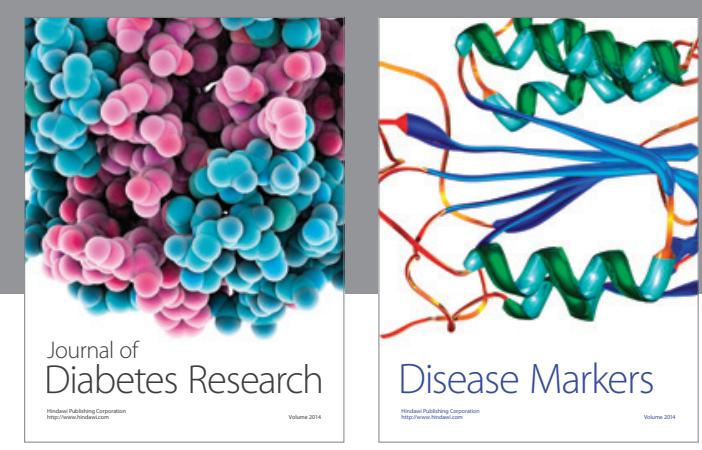

Disease Markers
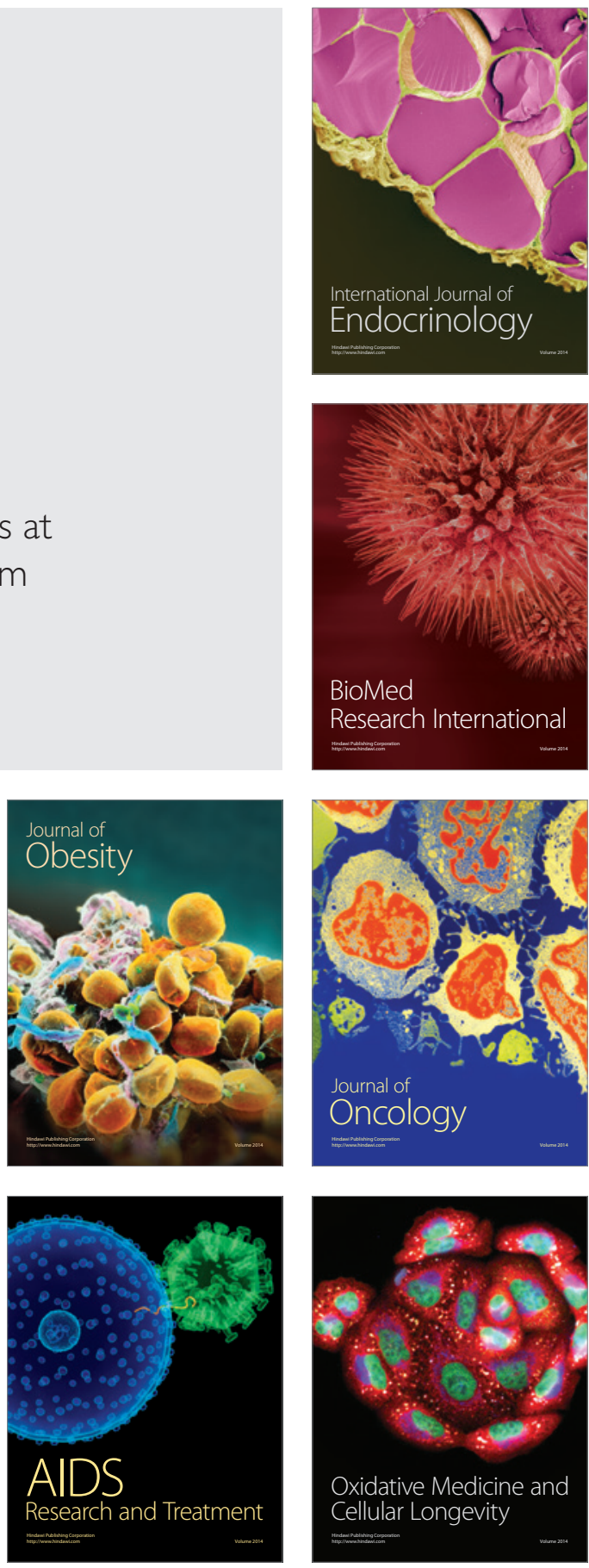